\title{
Tinnitus in adolescents and its relation to the use of personal sound systems
}

\author{
Renata Almeida Araujo Silvestre ${ }^{1}$ \\ Angela Ribas ${ }^{2}$ \\ Jair Mendes Marques ${ }^{3}$ \\ Adriana Bender Moreira de Lacerda ${ }^{4}$
}

\begin{abstract}
Introduction: References to recreational exposure to high sound pressure levels (SPL) and the risk of hearing loss and sensation of tinnitus has increased in the adolescent population. Objective: To identify the occurrence of tinnitus in adolescents who use personal sound systems (PSS). Material and Methods: This was a descriptive cross-sectional study, using a sample of 153 normal-hearing adolescent students. Participants answered a selfadministered questionnaire containing open and closed questions, addressing information regarding sound habits with the use of PSS and symptoms associated with this practice. Results: The occurrence of a habit of using PSS was $93 \%$. Comparing the exposed and unexposed groups, the incidence of tinnitus was $40 \%$ and $33 \%$ respectively, and $22 \%$ reported the occurrence of tinnitus induced by the use of PSS. There was no significant difference for the presence of tinnitus depending on the degree of exposure. Conclusion: Although no relation between the use of PSS with tinnitus has been observed, the prevalence of symptoms of up to $40 \%$, including noise-induced episodes, reinforces the possibility of subclinical hearing loss induced by high NPS and, because of the irreversible nature of these losses, the urgency of educational and regulatory measures to reverse these habits and attitudes.
\end{abstract}

Keywords: adolescent, hearing, MP3-player, tinnitus.

\footnotetext{
${ }^{1}$ ENT, Student in Master's Program in Communication Disorders - Tuiuti University of Parana - Curitiba - PR - Brasil. E-mail: renatasaa@hotmail.com

2 Speech-Language Pathologist, PhD in Environment and Human Development, Professor of the Graduate Program in Communication Disorders - Tuiuti University of Parana - Curitiba - PR - Brasil.

${ }^{3}$ Mathematician, PhD in Geodetic Sciences, Professor of the Graduate Program in Communication Disorders - Tuiuti University of Parana - Curitiba - PR - Brasil.

${ }^{4}$ Speech-Language Pathologist, PhD in Biomedical Sciences, Professor of the Graduate Program in Communication Disorders - Tuiuti University of Parana -

Curitiba - PR - Brasil.

Institution: Tuiuti University of Parana.

Send correspondence to:

Renata Almeida Araújo Silvestre.

Rua Alvaro Andrade, 225, apt 1148, Portao, Curitiba - PR. Postal Code 80610240, Telephone (+55 41) 9915-3854

Paper submitted to the ITJ-SGP (Publishing Management System) on September 17, 2014;

and accepted on September 27, 2014. cod. 170
} 


\section{INTRODUCTION}

Tinnitus corresponds to sound perception, in the head or ear, without corresponding environmental stimuli'. Worldwide prevalence statistics indicate that $10 \%$ to $20 \%$ of the population exhibits the symptom ${ }^{2,3}$, and although there is positive relationship with age, the number of adolescents who have experienced at least one episode of temporary tinnitus induced by high sound pressure levels (SPL) reaches almost $75 \%$ in some samples ${ }^{4}$.

The concern about the habits and attitudes related to recreational exposure to high SPL has been growing in the world, including the creation of normative characteristics for legislating personal sound systems (PSS) in European Union countries ${ }^{5}$.

However, the popularization in the use of PSS because of lower prices, increased storage capacity, easy downloads, increased power and reduced size of the devices has increased over time as has the sound intensity of exposure, especially among the younger population ${ }^{6}$, so that the prevalence of PSS is about $95 \%$ in some populations ${ }^{7,8}$.

Although there are no regulations related to recreational exposure to noise, taking as a basis the reference values used for occupational exposure, approximately half of adolescents have had exposure that is higher than recommended safe limits for hearing health, and a third of them are subject to this exposure through the use of PSS ${ }^{8}$.

This deleterious behavior has been associated with situations involving a desire for acceptance and integration within a group, need for isolation, improving self-esteem through the euphoria due to high-intensity sound stimulus, socioeconomic factors, among others ${ }^{6-11}$.

The situation becomes even more worrisome in light of suggestions from current research, suggesting greater susceptibility of younger people to hearing damage and greater predisposition to the development of hearing loss in adulthood when there is early exposure to high noise levels ${ }^{5,12}$.

Given that tinnitus may be due to temporary or permanent noise-induced hearing loss, and can act as a warning sign even before clinical signs of hearing loss ${ }^{13}$, we sought to study the relationship between exposure to recreational noise and the occurrence of this symptom.

Thus, this study aims to describe the relationship of the habit of using PSS and tinnitus in a group of adolescents, and to correlate the presence of symptoms with exposure to high sound pressure levels caused by the use of such devices.

\section{METHOD}

This is a descriptive cross-sectional study that was approved by the Ethics in Research Committee under the CEP record number 2576.183/2011-08. All participants signed a consent form authorizing the use of data collected after clarification of the research objectives and the procedures to be used.

Invited to participate in the study were all teenage students present in a state school in the city of Curitiba on the days of evaluation, of both genders. Subjects who met the following criteria were included in the sample: signing the consent form, showing normal results from an ENT examination, from an acoustic impedance evaluation, and from a pure tone audiometry.

The evaluation was performed by an ENT doctor and paid special attention to the sinonasal structures and the outer and middle ear, with a cleaning of the external auditory canal being performed when necessary.

The audiological assessment was for normal thresholds up to $25 \mathrm{~dB} \mathrm{HL}$, per the classification of Lloyd and Kaplan (1978), obtained by pure tone audiometry, performed with an Otometrics Madsen Itera II device, TDH39 headphones, calibrated in soundproof booth treated in accordance with the standards required by the Federal Board of Speech (2010). For the measurements of acoustic impedance of the middle ear, an Interacoustics AT22 analyzer was used and found to be compatible with the normal type A tympanogram results, according to the classification from Jerger (1970).

Students included in the selection criteria were invited to complete a self-administered questionnaire containing open and closed questions, addressing their sound habits regarding the use of PSS, including information on commonly used intensity, frequency and duration of use, type of earphones, and symptoms associated with exposure, highlighting the presence of tinnitus. The visual analog scale was employed for estimating the volume range commonly used by the study subjects. Questions that arose were answered by the research team.

Results were statistically analyzed by Chi-squared and Difference of Proportions tests, at a significance level of 0.05 , and they are presented below.

\section{RESULTS}

One hundred and thirty four adolescents met the inclusion criteria, and of these, 125 (93.28\%) responded affirmatively to having the habit of using PSS. Of the nine subjects without exposure to music through PSS, three (33.33\%) reported having already experienced at least one episode of tinnitus during life. The prevalence of tinnitus according to the habit of using PSS is shown in Table 1. 
Table 1. Prevalence of tinnitus and use of personal sound systems (PSS).

\begin{tabular}{lccccc}
\hline $\begin{array}{l}\text { PSS } \\
\text { use }\end{array}$ & \multicolumn{2}{c}{$\begin{array}{l}\text { With tinnitus } \\
(\mathrm{n}=53)\end{array}$} & \multicolumn{2}{c}{$\begin{array}{c}\text { Without tinnitus } \\
(\mathrm{n}=81)\end{array}$} & $p$ \\
& $\mathrm{n}$ & $\%$ & $\mathrm{n}$ & $\%$ & 0.6928 \\
\hline Yes & 50 & 94.3 & 75 & 92.59 & - \\
No & 03 & 5.67 & 06 & 7.41 & - \\
TOTAL & 53 & 100.00 & 81 & 100.00 &
\end{tabular}

Chi-squared test, level of significance of 0.05

For purposes of statistical analysis, with respect to the occurrence of tinnitus in relation to the using PSS, the sample was divided by degrees of exposure with a regarding duration, intensity, and type of earphones used.

Thus, among PSS users, there were 63 female subjects and 62 male, between 12 and 17 years old, with a mean age of 14.72 years. Table 2 contains the distribution by gender and age of the exposed sample.

Table 2. Sample by age and gender.

\begin{tabular}{lccccc}
\hline \multirow{2}{*}{ Age } & \multicolumn{2}{c}{ Female $(\mathrm{N}=63)$} & \multicolumn{2}{c}{ Male $(\mathrm{N}=62)$} & $p$ \\
& $\mathrm{n}$ & $\%$ & $\mathrm{n}$ & $\%$ & 0.9848 \\
\hline 12 & 02 & 3.17 & 02 & 3.23 & 0.1569 \\
13 & 13 & 20.63 & 07 & 11.29 & 0.3142 \\
14 & 17 & 26.98 & 12 & 19.35 & $0.0473^{\star}$ \\
15 & 14 & 22.22 & 24 & 38.71 & 0.9673 \\
16 & 11 & 17.46 & 11 & 17.74 & 0.9758 \\
17 & 06 & 9.52 & 06 & 9.68 & - \\
TOTAL & 63 & 50.04 & 62 & 49.60 &
\end{tabular}

Difference of Proportions test, level of significance of 0.05 .

We observed that $64.8 \%$ of adolescents have experienced at least one otological symptom, with tinnitus prevalence of $40 \%$, followed by pain ear, ear fullness, itching, dizziness, and hearing loss. However, with regard to the occurrence of symptoms due to the use of PSS, 49 subjects (39.2\%) reported at least one otological complaint, and the highest frequency was again tinnitus, occurring in $21.6 \%(n=27)$ of subjects.

For exposure time (years, days and hours), $60 \%(n=$ 75) of the students reported having used a PSS for less than three years and $56.8 \%(n=71)$ use it for less than two hours per day. However, $74.42 \%(n=93)$ claim to listen to music on their PSS at least five days a week. The association of tinnitus with the exposure time on a PSS is shown in Table 3.

Questioned as to the intensity usually used on their PSS, almost all the subjects, $92.8 \%(n=125)$, use their stereos at moderate to high-intensity volumes, and $27.2 \%(n=34)$ use the maximum volume of the device. In Table 4 we see the relationship with the presence of tinnitus.
Table 3. Association of tinnitus with exposure time (years, days and hours) of PSS use.

\begin{tabular}{lccccc}
\hline \multirow{2}{*}{ Exposure time for PSS } & \multicolumn{7}{c}{ With tinnitus } & \multicolumn{4}{c}{ Without tinnitus } & \\
& $\mathrm{n}$ & $\%$ & $\mathrm{n}$ & $\%$ & $p$ \\
\hline Less than 3 years & 28 & 56.00 & 47 & 62.67 & 0.4561 \\
More than 3 years & 22 & 44.00 & 28 & 37.33 & \\
Up to 4 days/week & 16 & 32.00 & 16 & 21.33 & 0.1807 \\
5 or more days/week & 34 & 68.00 & 59 & 78.67 & \\
Less than 2 hours/day & 28 & 56.00 & 43 & 57.33 & 0.8828 \\
2 or more hours/day & 22 & 44.00 & 32 & 42.67 & - \\
\hline
\end{tabular}

Chi-squared test, level of significance of 0.05 .

Table 4. Association of tinnitus with volume (SPL) used in PSS, based on visual analog scale graduated from 0 to 10 .

\begin{tabular}{lccccc}
\hline \multirow{2}{*}{ Intensity } & \multicolumn{2}{l}{ With tinnitus } & \multicolumn{2}{c}{ Without tinnitus } & $p$ \\
& $\mathrm{n}$ & $\%$ & $\mathrm{n}$ & $\%$ & \\
\hline $1-3$ & 04 & 8.00 & 05 & 6.67 & 0.7837 \\
$4-7$ & 20 & 40.00 & 35 & 46.67 & 0.4631 \\
$8-10$ & 26 & 52.00 & 35 & 46.67 & 0.5848 \\
TOTAL & 50 & 100.00 & 75 & 100.00 & - \\
\hline \multicolumn{5}{l}{ Difference of Proportions test, level of significance of 0.05. }
\end{tabular}

With respect to the type of earphones used, $73 \%$ of the sample prefer ear-plug style models $(n=91)$, followed by ear-muff style models with $20 \%(n=25)$ and $7 \%(n=$ 9) opting to use both types. The presence of tinnitus according to the model of earphone used is shown in Table 5.

Table 5. Association of tinnitus with the type of earphone used.

\begin{tabular}{|c|c|c|c|c|c|}
\hline \multirow{2}{*}{ Type of earphone } & \multicolumn{2}{|c|}{ With tinnitus } & \multicolumn{2}{|c|}{ Without tinnitus } & \multirow[t]{2}{*}{$p$} \\
\hline & $\mathrm{n}$ & $\%$ & $\mathrm{n}$ & $\%$ & \\
\hline Insertion & 37 & 74.00 & 54 & 72.00 & 0.8060 \\
\hline Earmuff & 12 & 24.00 & 13 & 17.33 & 0.3618 \\
\hline Both & 01 & 2.00 & 08 & 10.67 & 0.0686 \\
\hline TOTAL & 50 & 100.00 & 75 & 100.00 & - \\
\hline
\end{tabular}

Difference of Proportions test, level of significance of 0.05 .

Attempting to correlate the prevalence of tinnitus with the habitual use of PSS, by applying the Chi-squared test, at a significance level of 0.05 , for the groups with and without exposure variables of duration of habit, there was not a statistically significant difference observed. Similarly, using the Difference of Proportions Test, at a significance level of 0.05 , for the variables of intensity and type of earphone used, no significant difference was found.

\section{DISCUSSION}

The popularization of the use of PSS, particularly in younger populations and the lack of regulation regarding the maximum intensity output for these devices have 
contributed to an increase in the risk to hearing health from voluntary recreational exposure to loud noise in this age group $6,14,15$.

Note that the prevalence of habitual PSS use is $93.28 \%$ in the study sample and that these high numbers have been repeated in other studies with similar age groups in different countries, with values ranging from $90 \%$ to $95.6 \%^{7-9}$, although, depending on the selection criteria, the next lowest values can be found at $50 \%{ }^{16}$.

Given the knowledge of the deleterious potential of high SPL in hearing health, respecting, of course, differences in individual susceptibility ${ }^{17}$, it is relevant to estimate that about $10-30 \%$ of PSS users are at risk of $\mathrm{NIHL}$ after 5 or more years of use due to exposure to high-intensity noise over a long period of time ${ }^{9,18}$. Since the occurrence of otological symptoms can signal temporary or permanent subclinical hearing damage, the high prevalence of otological symptoms (64.8\%) among our subjects stands out, although some studies have shown results up to $67.2 \%^{14}$.

Noteworthy is the presence of tinnitus, not only for its known etiology related to hearing loss, even if it is not clinically apparent, but by its increasing prevalence among younger populations, appearing as the most reported symptom in most studies ${ }^{14,19}$. Although, depending on the methodology used, the numbers of spontaneous tinnitus in studies involving adolescents have varied from $7.5 \%{ }^{20}$ to $74.9 \%^{4}$, the prevalence observed in our sample, $40 \%$ of PSS users and $33 \%$ among non-PSS users, coincides with most studies which varied from $35 \%$ to $38.4 \%^{16,21}$. It is noteworthy that although more prevalent in the exposed group, by Chi-squared test, at a significance level of 0.05 , showed no significant difference was observed in the presence of tinnitus related to PSS use, in opposition to results demonstrated by other authors ${ }^{22}$.

Dealing specifically with noise-induced tinnitus, we see occurrence in $21.6 \%$ of the sample, coinciding with other studies $22-24$ and raising an alert to the possibility of these episodes being linked to the occurrence of TTS (temporary threshold shift) and PTS (permanent threshold shift).

The PSS usage profile was within the expected range for the adolescent population ${ }^{7,8,14}$, using the devices at least five days a week at a high volume, even though it has been for a few years. This presence of positive attitudes toward noise, with higher prevalence of abuse in the use of PSS, has been related to worse socioeconomic conditions and family structure, besides being justified in certain situations, by the pleasurable sensation provided by exposure to high SPL, providing social isolation and developing a vicious cycle dependent on force of habit ${ }^{11}$. Because of the possibility of this habit becoming linked to dependence, we emphasize the importance of acting on this population, despite having little time of noise exposure, which uses PSS in a way that is extremely harmful to hearing health.

With regard to the preferred sound intensity of use, it is relevant to highlight the finding of correspondence between the volume setting on PSS reported by users using a visual analog scale and its laboratory confirmation, especially in noisy environments, as demonstrated in some studies ${ }^{25,26}$ although other authors have observed an overestimation of the volume used ${ }^{27}$.

Almost all teenagers of both genders, have indicated the habit of regulating volume between moderate and high, coinciding with other authors' findings about attitudes of young people and adolescents regarding noise, in which only $10 \%$ of the sample states to using PSS at low intensity ${ }^{14}$. That is extremely worrying given, considering that the volume output is as high as $126 \mathrm{~dB} \mathrm{HL}$ in some devices, which according to regulations for $\mathrm{NIHL}$, reduces the time for safe continuous use to less than one minute ${ }^{24}$.

As for the earphones used, the preference for insertion (earplug) models observed in $72.8 \%$ of the sample has been shown to be a global trend ${ }^{28}$. The importance of this finding is due to the knowledge that the use of the insertion earphone, for having less attenuation to ambient sounds, ends up raising the sound pressure level for the user, in addition to causing an increase of up to $10 \mathrm{~dB}$ compared the earmuff type $\mathrm{e}^{5,25}$.

Comparing the presence of tinnitus among subjects with and without exposure to PSS and between more and less exposed groups, we observed no difference in the prevalence of tinnitus symptoms, coinciding with other studies ${ }^{26}$, although some authors have identified a positive correlation with PSS abuse and the presence of tinnitus when the subject has been exposed for a longer time ${ }^{14,19}$, at higher intensities ${ }^{8}$, and using insertion-style earphones ${ }^{29}$ or only between the groups with and without exposure to PSS ${ }^{22}$.

It was questioned if the exposure time would have been insufficient to cause increased occurrence of symptoms since it has been shown that hearing quality deterioration occurred only in PSS users of more than 5 years ${ }^{7,29}$. Moreover, in the present study, other forms of recreational and environmental exposure to loud sound, which could be responsible for generating heterogeneity of groups and result in lack of significant findings were not taken into account.

\section{CONCLUSION}

The occurrence of the habit of listening to music through PSS corresponds to almost all adolescent subjects (93.28\%). Even though most started habitual PSS use less than three years prior, the use several days a week, at high volume intensities, and using insertion-style earphones, may cause harm to hearing health in this population. 
Although no relation between the use of PSS and tinnitus has been observed, the prevalence of symptoms of up to $40 \%$, including noise-induced episodes, reinforces the alert to the possibility of subclinical hearing loss induced by high SPL, and because of the irreversible nature of these losses, it is urgent to take educational and normative steps to reverse these harmful habits and attitudes measures.

\section{REFERENCES}

1. Mendes Rde C, Ribas A, de Macedo IP, Buschle M, Ataíde AL, Pereira $R$, et al. Cochlear implant in the treatment of incapacitating unilateral tinnitus: case report. Int Tinnitus J. 2012;17(2):200-4. DOI: http://dx.doi.org/10.5935/0946-5448.20120035

2. Faculdade de Medicina da Universidade de São Paulo [Cited Jul 21, 2014]. Available from: http://www.zumbido.org.br/

3. Hearing Health Foundation [Cited Jul 21, 2014]. Available from: http://hearinghealthfoundation.org/statistics/

4. Gilles A, Van Hal G, De Ridder D, Wouters K, Van de Heyning P. Epidemiology of noise-induced tinnitus and the attitudes and beliefs towards noise and hearing protection in adolescents. PLoS One. 2013;8(7):e70297.

5. Khatter K. Personal music players and hearing loss: are we deaf to the risks? Open Med. 2011;5(3):e137-8.

6. Levey S, Fligor BJ, Cutler C, Harushimana I. Portable music player users: cultural differences and potential dangers. Noise Health. 2013;15(66):296-300.

7. Kim MG, Hong SM, Shim HJ, Kim YD, Cha CI, Yeo SG. Hearing threshold of Korean adolescents associated with the use of personal music players. Yonsei Med J. 2009;50(6):771-6. PMID: 20046416

8. Sunny OD, Asoegwu CN, Abayomi SO. Subjective tinnitus and its association with use of ear phones among students of the College of Medicine, University of Lagos, Nigeria. Int Tinnitus J. 2012;17(2):169-72.

9. Vogel I, Verschuure H, van der Ploeg CP, Brug J, Raat H. Estimating adolescent risk for hearing loss based on data from a large schoolbased survey. Am J Public Health. 2010;100(6):1095-100. DOI: http://dx.doi.org/10.1093/her/cyq091

10. Pellegrino E, Lorini C, Allodi G, Buonamici C, Garofalo G, Bonaccorsi G. Music-listening habits with MP3 player in a group of adolescents: a descriptive survey. Ann Ig. 2013;25(5):367-76.

11. Vogel I, Brug J, Van der Ploeg CP, Raat H. Adolescents risky MP3player listening and its psychosocial correlates. Health Educ Res. 2011;26(2):254-64.

12. van Kamp I, Davies $H$. Noise and health in vulnerable groups: a review. Noise Health. 2013;15(64):153-9.

13. Sliwinska-Kowalska M, Davis A. Noise-induced hearing loss. Noise Health. 2012;14(61):274-80.
14. Luz TS, Borja ALVF. Sintomas auditivos em usuários de estéreos pessoais. Int Arch Otorhinolaryngol. 2012;16(2):163-9.

15. Zucki F, Morata TC, Santos LMO, Isleb MHM. A perda auditiva induzida pela música (PAIM) e a busca de promoção da saúde auditiva. In: Morata TC, Zucki F. Saúde auditiva: Avaliação de riscos e prevenção. São Paulo: Plexus; 2010. p.37-60.

16. Lacerda ABM, Gonçalves CGO, Zocoli AMF, Diaz C, Paula K. Hábitos auditivos e comportamento de adolescentes diante de atividades de lazer ruidosas. Rev CEFAC. 2011;13(2):322-9.

17. Seidman MD, Standring RT. Noise and quality of life. Int J Environ Res Public Health. 2010;7(10):3730-8.

18. Scientific Committee on Emerging and Newly Identified Health Risks. Potential health risks of exposure to noise from personal music players and mobile phones including a music playing function [Cited Jul 21, 2014], Available from: http://ec.europa.eu/ health/ph risk/committees/04 scenihr/docs/scenihr o 018.pdf

19. Coelho CB. Epidemiology of tinnitus in children. in: Møller AR, Langguth B, Deridder D, Kleinjung T, eds. Textbook of tinnitus. New York: Springer; 2011. p.39-45.

20. Mahboubi H, Oliaei S, Kiumehr S, Dwabe S, Djalilian HR. The prevalence and characteristics of tinnitus in the youth population of the United States. Laryngoscope. 2013;123(8):2001-8.

21. Juul JA. Hearing symptons in children and adolescents: tinnitus and temporary thresholds shifts [Thesis]. Gothenburg: University of Gothenburg, 2013. 85f.

22. Figueiredo RR, Azevedo AA, Oliveira PM, Amorim SP, Rios AG, Baptista V. Incidence of tinnitus in mp3 player users. Braz J Otorhinolaryngol. 2011;77(3):293-8.

23. Le Prell CG, Spankovich C, Lobariñas E, Griffiths SK. Extended high-frequency thresholds in college students: effects of music player use and other recreational noise. J Am Acad Audiol. 2013;24(8):725-39.

24. Breinbauer HA, Anabalón JL, Gutierrez D, Cárcamo R, Olivares C, Caro J. Output capabilities of personal music players and assessment of preferred listening levels of test subjects: outlining recommendations for preventing music-induced hearing loss. Laryngoscope. 2012;122(11):2549-56.

25. Portnuff $\mathrm{CD}$, Fligor BJ, Arehart $\mathrm{KH}$. Teenage use of portable listening devices: a hazard to hearing? J Am Acad Audiol. 2011;22(10):663-77.

26. Sulaiman $A H$, Seluakumaran $K$, Husain R. Hearing risk associated with the usage of personal listening devices among urban high school students in Malaysia. Public Health. 2013;127(8):710-5.

27. Muchnik C, Amir N, Shabtai E, Kaplan-Neeman R. Preferred listening levels of personal listening devices in young teenagers: self reports and physical measurements. Int J Audiol. 2012;51(4):287-93.

28. Kähäri KR, Aslund T, Olsson J. Preferred sound levels of portable music players and listening habits among adults: a field study. Noise Health. 2011;13(50):9-15.

29. Hanazumi A, Gil D, lório MCM. Estéreos pessoais: hábitos auditivos e avaliação audiológica. Audiol Commun Res. 2013;18(3):179-85. 